\title{
ПРОБЛЕМЫ ВОСПИТАНИЯ
}

Вестник ПСТГУ

IV: Педагогика. Психология

2014. Boin. 4 (35). C. 32-43

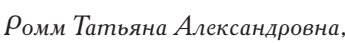
д- $\rho$ пед. наук, профессо, ИИГСО НГПУ tromm@mail.ru

\section{СТАНОВЛЕНИЕ И РАЗВИТИЕ \\ ИНТЕРПРЕТАТИВНОГО ОБРАЗА СОЦИАЛЬНОГО ВОСПИТАНИЯ В ОТЕЧЕСТВЕННОЙ ПЕДАГОГИКЕ ${ }^{1}$}

\author{
T. A. Ромм
}

\begin{abstract}
Неконвенциональность представлений о социальном воспитании, свойственная современному развитию педагогической науки, связана с уточнением методологических позиций, задающих способы осознания и восприятия педагогических феноменов. $\mathrm{Pa}-$ курс анализа сдвигается в сторону индивидуализированных характеристик социальных ситуаций и путей их преобразования. Для прояснения сущности феномена социального воспитания недостаточно обращения к эвристическим возможностям нормативнообъясняющей методологии (Э. Дюркгейм, Т. Парсонс и др.), реализация же иной исследовательской ориентации связана с интерпретативно-понимающим научным подходом (В. Дильтей, Дж. Г. Мид и др.), провозглашающим множественность проявлений любого социального феномена. В статье анализируются источники формирования интерпретативного теоретического образа социального воспитания, раскрываются особенности его становления и развития в отечественной педагогике.
\end{abstract}

\section{Актуальность темы}

Появление понятия «социальное воспитание» в современной педагогике сопряжено с необходимостью разрешения задач, которые возникают у человека по ходу социализации, а также с представлением о способах решения этих задач в педагогической науке². Неконвенциональность представлений о социальном воспитании, свойственная современному развитию педагогической науки, связана в первую очередь с уточнением методологических позиций, задающих

\footnotetext{
${ }^{1}$ Статья подготовлена при поддержке РГНФ, проект № 13-06-00162.

${ }^{2}$ См., напр.: Ромм T. A. Социальное воспитание в постиндустриальную эпоху // Вестник ПСТГУ. Серия IV: Педагогика. Психология. 2009. Вып. 3. С. 15-25; Она же. Формирование теоретических образов социального воспитания как научно-педагогическая проблема // Сибирский педагогический журнал. 2006. № 1. С. 129-137; Склярова Т. В. Традиции религиозной педагогики в исследовании социального воспитания // Сибирский педагогический журнал. 2014. № 4. С. 35-38 и др.
} 
Т. А. Ромм. Становление и развитие интерпретативного образа социального воспитания...

способы осознания и восприятия педагогических феноменов. Утверждающийся постнеклассический рационализм, пришедший на смену неклассической рациональности, сменившей (вернее, «снявшей») в свою очередь рациональность классическую, не только значительно расширил, но и усложнил миропонимание современного человека, обусловливая необходимость выработки новых методологических принципов и ценностно-целевых установок.

В этой связи можно утверждать, что современная теоретизация социального воспитания учитывает разнонаправленные исследовательские установки в сущностном понимании феноменов социального, личности и воспитания, которые в той или иной степени тяготеют к двум ведущим общенаучным подходам. В разных классификациях эти, уже ставшие традиционными, парадигмы обозначаются по-разному: как объективизм и субъективизм, макро- и микроуровни анализа, «нормативизм» и «интерпретативизм», «объясняющий» и «понимающий» ${ }^{3}$.

Нормативный общенаучный исследовательский подход заложен традицией позитивизма и свое развитие получил в концепциях Э. Дюркгейма, Т. Парсонса и Р. Мертона. Основы интерпретативного анализа, зародившиеся в «понимающей социологии» М. Вебера и «философии жизни» В. Дильтея, приводят далее к «символическому интеракционизму» Дж. Г. Мида и обретают законченный вид в трудах таких социологов и философов феноменологической и герменевтической ориентации, как Э. Гуссерль и Г.-Х. Гадамер, И. Гофман и А. Шюц, П. Бергер и Т. Лукман, П. Рикер.

Исследовательская ориентация на классические, позитивистские (нормативные) идеи актуализирует абстрагирование социальных ситуаций от индивидуальных характеристик, их типичность, унифицированность; позволяет учесть объективные закономерности приобщения человека к нормам и ценностям общества. Для прояснения сущности феномена социального воспитания этого оказывается недостаточно. Ограниченность нормативно-объясняющей методологии заключается в том, что она позволяет обосновать специфику содержания социального воспитания с учетом только макрохарактеристик социального как извне задаваемых процессов, влияющих на человека и выражающихся в требовании приспособительных стратегий воспитания. Но подобная установка не позволяет в полной мере учесть субъективный план социальности, а также многообразие влияний и воздействий окружающего мира на человека в его рациональном и иррациональном существовании, ограничивает возможности воспитания рамками целенаправленной деятельности и ставит под вопрос сам факт признания существования социального воспитания как специфического вида.

Возможность реализации иной исследовательской ориентации связана с интерпретативно-понимающим научным подходом, провозглашающим множественность проявлений любого социального феномена.

${ }^{3}$ Ромм М. В., Ромм Т. А. Конструирование теоретических образов социальных феноменов // Вестник НГУ. Серия Философия. 2010. Т. 8. Вып. 2. С. 32-36. 
Исследования: педагогика

\section{Источники формирования интерпретативных основ теоретизации социального воспитания}

Истоки интерпретативных (как и нормативных) установок теоретизации социального воспитания связаны с «идейными комплексами», обозначившимися в доиндустриальную эпоху. Так, в античную эпоху, которая впервые обозначила проблему общественного характера воспитания и собственно общественного воспитания (Платон), Аристотелем привносится «психологический» аспект в трактовку социальных связей: по его мнению, государство выступает как своего рода общение, «некоторая форма общежития», в которой присутствует своеобразный тип общественных отношений - дружеских. «...Все сообщества, - отмечает Аристотель, имея в виду семью и другие временные “союзы”, - это как бы члены государственного сообщества <...> все взаимоотношения оказываются частями взаимоотношений в государстве (т. е. частями государственного сообщества). А этим частям соответствуют разновидности дружбы» ${ }^{4}$. Благодаря выделению некоего подобия психологического аспекта социальных связей Аристотель оказывается ближе к пониманию общества как сложной структуры.

Постепенное утверждение эллинистических идеалов привело к разрушению тождества «человек и гражданин», на смену ему пришла новая идентификация индивид, что в свою очередь повлекло утверждение индивидуально-духовных ценностей. Становление тенденции к усилению внимания к человеческой индивидуальности в философском осмыслении привело к развитию философскопедагогической рефлексии по поводу различий социально- и индивидуальноличностных механизмов социализации человека. Этому способствовало распространение христианского образа человека. «Религиозные традиции фиксируют и отражают в общественной жизни определенные ценности, - отмечает T. В. Склярова, - наряду с этим религиозная традиция может оказывать влияние на формирование определенных мировоззренческих установок конкретного

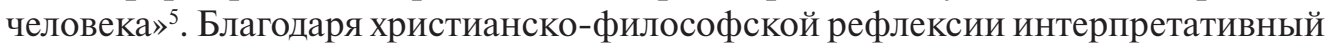
аспект социального воспитания расширяется.

Bo-nервых, наряду с утвердившимся в эпоху классической античности приоритетом рационального социально-актуального знания как компонента общественного воспитания, утверждающаяся религиозность актуализировала «практический», поведенческий аспект. В библейской среде центральной всегда была практическая цель (христианская мораль требовала от человека соответствующего практического поведения в обществе), поднятая на уровень сакральной ценности.

Во-вторых, христианская установка на интерес к отдельной личности, ее внутреннему миру стимулировала обращение к эмоциональной сфере человека, сфере переживаний, что также расширяло содержание общественного воспитания в части его духовно-ценностных ориентаций. Вместо акцента на рациональное научное знание доминирует акцент на спасение души и ее нравственное

\footnotetext{
${ }^{4}$ Аристотель. Никомахова этика // Соч.: В 4 т. М., 1984. Т. 4. С. 233-234.

${ }^{5}$ Склярова. Указ. соч. С. 35-38.
} 
Т. А. Ромм. Становление и развитие интерпретативного образа социального воспитания...

формирование, на добродетель и мудрость. Обучение человека было направлено не просто на Разум человека, а прежде всего - на его Волю. Учить мыслить значит воспитывать одухотворенность ежедневного поведения.

$B$-третьих, христианская практика представила миру особые механизмы социализации на уровне сочетания рационального и мистического компонентов (В. Г. Безрогов, Т. В. Склярова), с помощью которых человек способен оптимально взаимодействовать (адаптироваться и обособляться) с другими людьми и окружающим миром. Например, таким механизмом социализации человека выступала идея и принцип «Imitatio Christi» («подражание Христу») - неотъемлемый компонент средневекового воспитательного идеала. Или символизм, парадоксальность как один из способов дополнения или разрушения обыденного мировосприятия и мироотношения, формирования рефлексивности как основы ответственного (в том числе и социального) поведения. Такими ритуалами прежде всего были исповедь и проповедь. Они, с одной стороны, являлись средством выработки способности личности к самооценке; с другой стороны, при помощи исповеди и проповеди прихожане усваивали религиозные максимы и интериоризировали христианское учение. С точки зрения развития представлений о социальном воспитании важен момент существования особой воспитывающей среды - общины единомышленников как сообщества людей, стремящихся в идеале к совершенной жизни, совершенному поведению.

Углубление интерпретативно-понимающих оснований теоретических образов социального воспитания связано с развитием научной рациональности неклассического типа (В. А. Лекторский, Н. М. Смирнова, В. С. Степин и др.), для которой характерны:

- отказ от прямолинейных схем и признание относительности в понимании картины мира;

- допустимость истинности нескольких отличающихся друг от друга конкретных теоретических описаний одной и той же реальности;

- выяснение связей между новой и предшествующей ей теориями (принцип соответствия) вместо принципа наблюдаемости явлений;

- расширение поля исследуемых объектов (сложные саморегулирующиеся системы, характеризующиеся уровневой организацией, наличием относительно автономных и вариабельных подсистем, стохастическим взаимодействием, обратной связью);

- социальность как особый целостный организм, связанный с признанием эволюционных процессов развития человека (Г. Бергсон, В. Дильтей, Г. Зиммель, К. Ясперс и др.);

- «метод понимания» в социально-гуманитарном знании, ориентированный на описание уникальности социальных событий (М. Вебер, В. Дильтей);

- философско-антропологические идеи, акцентирующие контекст пространства и времени человеческой жизни (О. Больнов, М. Шелер, Х. Плеснер).

Для развития интерпретативных основ теоретизации социального контекста воспитания в отечественной педагогике особое значение имели интеллектуальные искания российского общества на рубеже XIX и XX вв., в которых наряду со взглядами революционных демократов, идеями научного социа- 
лизма и буржуазно-демократическими учениями Запада получили широкое распространение религиозно-космические идеи. Их подосновой являлся характерный для русского сознания мифологизм (именно в Космосе В. В. Розанов усматривал источник индивидуализации, а центром мироздания считал семью). Интерпретативный образ социального воспитания конструировался также на основе признания ценностей религиозной духовности как высшей и естественной социальности человека, примата индивидуального в его развитии (С. Р. Булгаков, С. И. Гессен, В. В. Зеньковский, Н. К. Рерих, В. С. Соловьев, Л. Н. Толстой и др.).

Дальнейшее развитие интерпретативно-понимающих основ теоретических образов социального воспитания происходит по мере появления в отечественной науке идей комплексности (Л. П. Буева и др.); распространения методологии системного подхода (Ю. К. Бабанский, Т. А. Ильина, Г. П. Щедровицкий, Ю. Конаржевский, Ф. Ф. Королев, В. В. Краевский, Л. И. Новикова, А. Т. Куракин и др.), идей кибернетики (С. Л. Соболев, А. Н. Колмогоров, А. Д. Урсул и др.); становления идеи социального творчества как неотъемлемого компонента социальной жизни; обращения психологии к проблемам соотношения индивидуального и общественного в аспекте личностного развития человека (С. Л. Рубинштейн, К. А. Абульханова-Славская и др.); исследования проблем социализации (Г. М. Андреева, С. С. Батенин, И. С. Кон, Ю. А. Левада, А. А. Петровский, Б. Д. Парыгин и др.). Все это способствовало утверждению необходимости и возможности гармонии личности и общества, в которой свободная, инициативная личность сознательно воспринимает мир, осознает свою принадлежность обществу и одновременно свою независимость от него, сознательно совершает свой нравственный выбор как социальный.

\section{Отечественная традиция интерпретативного осмысления социального воспитания}

Развитие интерпретативного теоретического образа социального воспитания тесно связано с антропологической установкой на рассмотрение педагогических явлений, заявленной К. Д. Ушинским. Утверждая целостность педагогического процесса, Ушинский выделяет в качестве составных его компонентов не только преднамеренную воспитательную деятельность (школа, воспитатель, наставники), но и «непреднамеренных воспитателей»: природа, семья, общество, народ, религия, язык: «словом, природа и история в обширнейшем смысле этих обширных понятий» ${ }^{6}$. Целостность человеческого характера, по мнению К. Д. Ушинского, складывается из взаимодействия природного и духовного компонента (последний формируется под влиянием воспитания и обстоятельств) $)^{7}$.

${ }^{6}$ Ушинский К. Д. О народности в общественном воспитании // Избр. пед. соч. М., 1953. C. 122 .

${ }^{7}$ Он же. Школьные реформы в Северной Америке // Собр. соч.: В 11 т. М.; Л., 1948-1954. Т. 2. Педагогические статьи 1857-1861. С. 122. 
Т. А. Ромм. Становление и развитие интерпретативного образа социального воспитания...

Конструирование социального воспитания как обеспечения неразрывной связи индивидуально развивающегося ребенка с людьми, перерастающей в солидарность с человечеством и выражающейся в творческой общественной деятельности, составило центральное ядро теории «свободного воспитания» К. Н. Вентцеля, которая исходит из признания коренной гармонии между индивидуальностью и миром.

Опираясь на философские идеи интуитивизма (А. Бергсон), согласно которым человек развивается благодаря прирожденному стремлению к цельности, непротиворечивости, путем раскрытия его генетически обусловленных сил («философия творческой воли»), российский педагог формирует представление о среде как о важнейшем факторе «пробуждения» ценностного, этического и поведенческого облика личности, самостоятельной нравственной воли. Стремление внутреннего мира личности к непротиворечивости и гармонии для К. Н. Вентцеля - залог непротиворечивости внешней (социальной) и внутренней (психологической) детерминант. Процесс достижения этого - «организация цельного опыта жизни».

В этой связи важным является понимание соотношения коллективного и индивидуального в воспитании. К. Вентцель подчеркивал, что общественное воспитание - это не «воспитание стадности», при котором личность утрачивает свое «Я», а воспитание, проникнутое сознанием того значения, которое имеет свободная индивидуальная личность как наивысшая ценность. Общественное воспитание «...будет поднимать личность от ступени механической и принудительной её солидарности с обществом до степени её свободной и сознательной солидарности»8. Чем большая гармония достигается в области коллективной воли, тем более свободной и независимой делается индивидуальная воля. «Процесс объединения сознательно действующих личностей в одно планомерно и сознательно действующее коллективное целое есть процесс все большего раскрепощения личностей, процесс большего расширения сферы свободной сознательной деятельности» 9 .

Общественность понимается как свободная «общественность самобытных индивидуальных личностей» (К. Н. Вентцель). Воспитание направлено на ее развитие через создание вокруг ребенка специальной «общественной» среды, фундаментом которой является коллективное творчество. Именно обществу принадлежит ведущее место в создании новой школы, которой отводится задача создания такого идеального строя общественной жизни, с помощью которого она воспитывает из своих питомцев представителей истинной общественности. Важное внимание уделяется проблеме интеграции усилий всего общества в построении новой школы, где ведущую роль играет родительская общественность.

Развитие социально-религиозных идей конца XIX - начала XX в. (С. Р. Булгаков, С. И. Гессен, В. В. Зеньковский, Н. К. Рерих, В. С. Соловьев, Л. Н. Толстой и др.) актуализировали представления о роли и месте религии в процессе социализации человека как процессе вхождения человека в духовный мир. Ориентация на ценности «приближенности к Богу» предопределяла единство антро-

${ }^{8}$ Вентцель $K$. H. Новые пути воспитания и образования детей. М., 1910. С. 50.

${ }^{9}$ Он же. Теория свободного воспитания и идеальный детский сад. М., 1915. С. 28. 
пологического и бытийно-космического (Н. Ф. Федоров) содержания философствования, что выразилось в итоге в вере в безграничную мощь человеческого разума, устремленного к Творцу, с утверждением бессмертия и абсолютной ценности каждой человеческой личности.

Утверждение понимания человека как центра Вселенной, космоса, «человека в Боге, а Бога в человеке» стимулировало представление о необходимости создания религиозного микросоциума путем религиозно-нравственного воспитания. «Социальный смысл воспитательного воздействия обнаруживается в том, что мы готовим дитя для жизни <...> а это значит, что мы должны, прежде всего, способствовать развитию в ребенке социальных сил его души, развитию в нем духа солидарности. Это нисколько не устраняет и не отодвигает задач развития индивидуальных способностей и особенностей ребенка, но только придает этой задаче новый смысл», - рассуждал В. В. Зеньковский в 1918 г. Преодоление дисгармонии в отношениях между людьми как антагонизма взаимоотношений человека и природы - вот задача социального воспитания.

Впоследствии религия и Церковь, став факторами национальной социализации и воспитания в условиях эмиграции, вызвали необходимость осмысления ее социально-педагогической роли в формировании детей и молодежи, изучения особенностей религиозной жизни детей и религиозного воспитания (Н. Н. Афанасьев, К. А. Ельчанинов, Л. А. Зандер, В. В. Зеньковский, С. С. Куломзина, прот. С. Четвериков, А. С. Четверикова и др.). Личность понимается как целостная, иерархическая система «дух - душа - тело», где приоритет отводится духовному началу. Именно в проявлениях духовной жизни ребенок усваивает наличие высших смыслов и ценностных ориентаций. Зеньковский пишет о «естественной социальности» человека, связывая ее с духовным началом (образом Бога, присутствующим в человеке изначально) и соборной природой человека. Эта социальность «начальнее отдельного человека» (В. В. Зеньковский), она возникает в общении людей на духовном уровне (В. В. Зеньковский называет это «социальным резонансом»), становится источником развития всех социальных процессов, «которые ведут к различным видам социального сближения и слияния». Высшая цель педагогики - раскрытие образа Божия в детях путем подготовки их к настоящей и будущей жизни. В то же время важнейшей задачей национального воспитания В. В. Зеньковский считал подготовку молодежи к служению Родине и отмечал многогранность и сложность этой проблемы.

Вообще эмиграция детей и подростков как социальный феномен не могла не стимулировать развитие социально-воспитательной проблематики. В педагогических концепциях представителей педагогики российского зарубежья ${ }^{10}$ актуализируется изучение факторов социализации личности в условиях эмиграции, причин утраты национальной идентификации и путей ее преодоления.

${ }^{10}$ См., напр.: Богуславский M. В. Трактовка национальных ценностей образования в наследии философов русского зарубежья (1920-1950-е гг.) // Национальные ценности образования: история и современность. М., 1996. С. 50-53; Осовский Е. Г. Российское зарубежье: педагогическая наука в изгнании (1920-1950-е годы XX в.) [Электронный ресурc.] URL: http:// pedagogics.narod.ru/obzor/zarub1.htm; Хрестоматия. Педагогика Российского Зарубежья. М., 1996. 
Т. А. Ромм. Становление и развитие интерпретативного образа социального воспитания...

На это было обращено исследование В. В. Зеньковского, С. И. Карцевского, Г. Я. Трошина (совместно со студентами) морально-психологического состояния детей-беженцев разного возраста ${ }^{11}$. На страницах педагогических журналов, выходивших в Праге («Русская школа за рубежом»), Берлине («Вестник самообразования»), Харбине («Вестник Маньчжурского Педагогического общества»), Париже («Религиозно-педагогический бюллетень») и др., активно обсуждались вопросы адаптации и социально-психологической реабилитации детей, оказавшихся в эмиграции; роль семьи, школы, религии в процессе их социализации.

В интерпретативном по содержанию образе социального воспитания решающим условием выступает не столько семья или школа, сколько создание соответствующего микросоциума, в котором религия обрела бы статус мощного фактора духовного возрождения личности. Его создание могло быть реализовано в организации приходской жизни детей и внешкольного религиозного образования, призванных компенсировать трудности воспитания в семьях эмиграции и сиротство ${ }^{12}$.

В первые десятилетия послеоктябрьского периода развитие интерпретативно-понимающих основ теоретического образа социального воспитания происходило также в русле основных идей антропологического знания, сложившегося в предыдущий исторический период. Особое значение в этом отводилось педологическим идеям (В. М. Бехтерев, П. П. Блонский, А. С. Залужный, А. Ф. Лазурский, С. С. Моложавый, А. П. Нечаев, Г. И. Россолимо и др.): попытке на основе знаний о ребенке разработать основы комплексной науки, которая стала бы методологией воспитания (учитывая биогенетические и социогенетические теории развития личности).

Интерпретативно-понимающий образ социального воспитания как попытка удержать связь между дореволюционной и послереволюционной традициями теоретизации свойственен взглядам Н. Н. Иорданского. Его трактовка социального воспитания основана на традиционной, для дореволюционного понимания, идее развития человека в среде (1919 г.: «социальное воспитание» не должно быть подменено «социалистическим воспитанием» $\left.{ }^{13}\right)$.

Мотив развития выразился в обосновании идеи воспитания социальнопсихологическими факторами (социальные инстинкты, повиновение товарищам, подражание, стремление к самостоятельности) и экономически-бытовыми факторами (осложнение быта и борьба за существование). Отталкиваясь от признания идеи развития человека, необходимости удовлетворения человеческой потребности в социальном, Иорданский, во-первых, разделяет общественное (социальное) и гражданское (государственное) воспитание, признавая за общественным и больший объем и большую широту. Гражданское и общественное

${ }^{11}$ Дети эмиграции / В. В. Зеньковский, ред. Прага, 1925.

12 Отчасти эта задача была решена путем создания школ интернатного типа (русскосербская гимназия в Белграде, гимназия «Моя маленькая Россия» в Шумене и др.); большую роль в ее решении сыграло Русское христианское студенческое движение: создание «русских домов», поддержка детских объединений (скауты, «витязи») и других форм социальнорелигиозной работы, создающих «русский» микросоциум.

${ }^{13}$ Иорданский Н. Н. Основы социального воспитания в народной школе. М., 1919. 
воспитание - это две ступени одного и того же явления в жизни души - проявления инстинкта общественности в человеке, существе по преимуществу типа «стадного» ${ }^{14}$. Направленность гражданского воспитания связана с признанием норм и подчинением им, направленность общественного - с уважением индивидуальных черт человека.

Важными условиями реализации общественного воспитания, по Н. Н. Иорданскому, выступают: общинный образ жизни, который складывается в школьной обстановке (дежурства по классу, украшения класса, организация бытовых вопросов, детские собрания), активность (трудовая, общественная, нравственная); развитие воли и эмоциональное подкрепление (переживание чувства ответственности за порученное дело и одновременно - умение «жить для себя»), самоуправление.

Механизм общественного воспитания начинается с момента фиксации проявления чувства и, через поддержку активности, его закрепление. На это может работать как учебная программа, так и внешкольная деятельность, и вся жизнь в многообразии проявлений. Н. Н. Иорданский уделял огромное значение так называемым «мелочам», говоря о том, что «от сложной организационной работы можно устраниться, а вот от мелочей жизни - никогда» ${ }^{15}$; многогранность и многообразие мелочей жизни позволяет сделать процесс социального воспитания неформализованным, доходящим до каждого человека. Показателен подход педагога к определению значимых сфер жизни ребенка, в которых осуществляется социальное воспитание: поскольку речь идет об удовлетворении человеческой потребности в общественности, то средства социального воспитания могут быть актуализированы во всех педагогических процессах через специальное целеполагание. В этом также состоит интерпретативно-понимающая направленность теоретического образа социального воспитания Н. Н. Иорданского.

Впоследствии признание значимости «природных» факторов в развитии человека (Б. Астауров, Н. П. Бочков, И. Т. Фролов, В. П. Эфроимсон) содействовало постепенному складыванию представлений о личности как об индивидуальном уровне общественного бытия (В. А. Крутецкий, В. Д. Небылицын, И. В. Равич-Щербо, Б. М. Теплов и др.). Не отрицая значения внешней детерминации личной жизни человека, психология начинает уделять внимание позиции человека как общественного субъекта. Так, использование термина «субъективное» означает для С. Л. Рубинштейна уникальность человека, присущая и психике, и познанию: «человек находится внутри бытия, а не только внешне его сознанию. В этом отношении бытие обступает нас со всех сторон» ${ }^{16}$. С. Л. Рубинштейн подчеркивал, что вообще неверно всякое рассуждение, которое выходит за пределы альтернативы: либо все изнутри, либо все извне; либо общественно заданные способы деятельности вовне, либо морфология тела изнутри. Для становления человеческой субъективности природное и общественное, социальное и биологическое - прежде всего предпосылки («материал»), из которых живущий человек строит принципиально другое, нечто третье, способствующее

\footnotetext{
${ }^{14}$ Иорданский. Указ. соч. С. 78.

${ }^{15}$ Там же. С. 43.

${ }^{16}$ Рубинштейн С. Л. Проблемы общей психологии. М., 1973. С. 262.
} 
Т. А. Ромм. Становление и развитие интерпретативного образа социального воспитания...

освоению (превращению в свое) и противостоящее ему (а не внутри находящейся) его собственной природности и его же собственной социальности.

Развивая идею субъективности личности, К. А. Абульханова-Славская вслед за В. Н. Мясищевым использует категорию «отношение», которое опосредует жизнедеятельность личности, ее общение и деятельность. «Только понятая через совокупность этих разных отношений к миру, личность может рассматриваться в своем отношении к деятельности. Анализ этого отношения возможен только на основе предварительного различения активности личности и ее деятельности» ${ }^{17}$. Соглашаясь с исходной диалектико-материалистической установкой об общественной сущности личности (как части коллективного субъекта), одной из важнейших форм включения личности в деятельность будет формирование отношения личности к деятельности. В этом случае актуализируется весь комплекс субъективных проявлений (жизненные ценности, субъективные потребности, чувственно-практический характер деятельности и пр.), от которых зависит успешность ее общественного существования.

\section{Заключение}

Реализация интерпретативной составляющей воспитания в современной педагогике связана с усилением значимости субъектной направленности всех его компонентов, что стало возможным благодаря развитию феноменологического направления в педагогике (И. Д. Демакова, А. Ф. Закирова, Л. М. Лузина, и др. ${ }^{18}$. Включение в теоретический анализ проблем социального воспитания феноменологических основ создает возможность осмысления индивидуальных характеристик социальной ситуации, которая приобретает характер неповторимости, единичности. В связи с этим актуализируются коммуникативные, эмоциональные, смысловые аспекты контролируемой и направляемой социализации. Очевидно, что любой человек, чтобы быть принятым группой, должен получить в процессе социализации знания не только о структуре и значении социальных элементов, но и о возможной их интерпретации. Следовательно, целенаправленное влияние на процесс социализации также не ограничивается передачей знаний, а простирается в сферу эмоций, смыслов, понимания. Процессы смыслообразования (Д. А. Леонтьев, Ф. Е. Василюк, Дж. Келли, В. Франкл и др.) приобретают характер социально образующих.

Герменевтическая ориентация позволяет актуализировать процессы смыслообразования как социально-воспитательные средства, позволяющие человеку обрести свое место в мире не только путем следования социально заданной норме, традиции, но и путем актуализации субъективных значений (смыслов), возникающих у человека в процессе взаимодействия с миром, переопределения и «вписывания» этих смыслов в общее «смысловое» поле взаимодействующих субъектов.

${ }^{17}$ Абульханова-Славская. Деятельность и психология личности. М., 1980. С. 232.

${ }^{18}$ Ромм. Феноменологические основы анализа социального воспитания // Философия образования. 2011. № 5 (38). С. 5-13. 
Подобный теоретический образ социального воспитания проблематизирует уточнение человеком своей социальной идентичности в процессе конструирования непротиворечивого мира вокруг себя, где личность выступает как творческое и активное образование, которое формирует свою среду в зависимости от собственных представлений об окружающих вещах. В связи с этим на первый план для социального воспитания выступает проблема обучения личности самоопределению и самореализации в тех условиях, в которых ей предстоит существовать. И само социальное воспитание выступает как «мост», соединяющий социально-психологический мир субъективных интерпретаций, самооценок и притязаний с миром объективной социальной реальности.

Ключевые слова: социальное воспитание, нормативный подход, интерпретативный подход.

\section{FORMATION AND DEVELOPMENT OF INTERPRETIVE IMAGE OF SOCIAL EDUCATION IN DOMESTIC PEDAGOGICS}

\section{T. Romm}

Unconventional ideas about the social education of a modern development of pedagogical science, associated with the specification of methodological positions that define the ways of awareness and perception of pedagogical phenomena. Analysis shifts toward individualized characteristics of social situation. For understanding the phenomenon of social education enough appeal to the the normative methodology (E. Durkheim, T. Parsons). Implementation of a research orientation is related to interpretively-understand scientific approach (W. Dilthey, G. H. Mead) proclaiming. multiplicity of manifestations of any social phenomenon. The article analyzes the sources of the interpretive theoretical image of social education; reveals the features of its formation and development in the national pedagogy.

Keywords: social education, the standard approach, the interpretive approach.

\section{Список литературы}

1. Абельс X. Интеракция, идентичность, презентация: введение в интерпретативную социологию. СПб., 1999.

2. Бергер П., Лукман Т. Социальное конструирование реальности. М., 1995.

3. Богданова E. B., Ромм T. A. Социальное воспитание в трансформирующемся обществе: Монография. Новосибирск, 2012.

4. Василюк Ф. Е. Психология переживания. М., 1984. 
Т. А. Ромм. Становление и развитие интерпретативного образа социального воспитания...

5. Вебер М. «Объективность» социально-научного и социально-политического познания // Избранные произведения. М., 1990. С. 345-415.

6. Гуссерль Э. Собрания соч.: Т. 3 (1). Логические исследования. Т. 2 (1). М., 2001.

7. Демакова И. Д. Междисциплинарный подход в теории воспитания: в поисках новой методологии // Вопросы воспитания. 2012. № 1 (10). С. 14-19.

8. Дильтей В. Герменевтика и теория литературы: В 6 т. М., 2001. Т. 4.

9. Дюркгейм Э. О разделении общественного труда: метод социологии. М., 1991.

10. Закирова $A$. Ф. Педагогическая герменевтика: социокультурный контекст и научнообразовательная практика // Вестник Тюменского государственного университета. 2010. № 5. С. 4-10.

11. Леонтьев Д. А. Психология смысла: природа, строение и динамика смысловой реальности. М., 2003.

12. Мид Дж. Г. От жеста к символу // Американская социологическая мысль: Тексты. М., 1996. С. 213-222.

13. Мудрик A. B. Мои методологические штудии // Социальная педагогика: люди, идеи, проблемы: сборник / Т. А. Ромм, Т. Т. Щелина, общ. ред. Арзамас: изд. АГПИ, 2011. C. 76-92.

14. Парсонс T. О структуре социального воздействия. М.: Академический проект, 2000.

15. Рикер П. Конфликт интерпретаций: очерки о герменевтике. М., 2002.

16. Ромм М. В., Ромм Т. А. Конструирование теоретических образов социальных феноменов // Вестник НГУ. Серия: Философия. 2010. Т. 8. Вып. 2. С. 32-36.

17. Ромм T. A. Социальное воспитание в постиндустриальную эпоху // Вестник ПСТГУ. Серия IV: Педагогика. Психология. 2009. Вып. 3. С. 15-25.

18. Склярова T. В. Традиции религиозной педагогики в исследовании социального воспитания // Сибирский педагогический журнал. 2014. № 4. С. 35-38.

19. Смирнова Н. М. Классическая парадигма социального знания и опыт феноменологической альтернативы // Общественные науки и современность. 1995. № 1. С. 127-137.

20. Степин В. С. Теоретическое знание. М., 2000.

21. Шюи $A$. Смысловая структура повседневности: Очерки по феноменологической социологии: [Пер. с англ.]. М., 2003.

22. Fischer A. Descriptive Pedagogik // Denkformen und Forschungsmethoden in der Erziehungswissenschaft. München, 1966. S. 83-99. 